\title{
Hubungan Informasi dan Umur dengan Kecemasan Ibu Kanker Payudara pada Tindakan Kemoterapi di Rumah Sakit Umum Daerah Zainoel Abidin
}

\author{
Information and Age Relationship with Maternal Breast Cancer Anxiety in \\ Chemotherapy Measures at Zainoel Abidin Regional General Hospital \\ Chairanisa Anwar ${ }^{* 1}$, Fina Laifa ${ }^{2}$ \\ ${ }^{1}$ Fakultas Ilmu Kesehatan, Universitas Ubudiyah Indonesia, Jalan Alue Naga Desa Tibang, Banda Aceh, Indonesia \\ ${ }^{2}$ D-IV Kebidanan Poltekkes Kemenkes Aceh \\ *Korespondensi Penulis: chaira.anwar@uui.ac.id
}

\begin{abstract}
Abstrak
Data WHO tahun 2011 memperkirakan angka kejadian yang terkena kanker payudara terdapat 11 juta dan tahun 2030 akan bertambah menjadi 27 juta kematian akibat kanker. Di Indonesia, data global burden of cancer (globocan), kanker payudara merupakan kanker yang terbanyak terjadi pada perempuan (26 per 100.000). Di Aceh khususnya RSUD Zainoel Abidin sebanyak 809 orang yang menderita kanker payudara, yaitu : 361 orang rawat inap dengan jumlah kunjungan triwulan I 129 orang, triwulan II 88 orang, triwulan III 61 orang, triwulan IV 75 orang dan 448 orang rawat jalan dengan jumlah kunjungan triwulan I 97 orang, triwulan II 208 orang, triwulan III 72 orang, triwulan IV 89 orang. Untuk mengetahui hubungan informasi dan umur dengan kecemasan ibu kanker payudara pada tindakan kemoterapi di Rumah Sakit Umum Daerah Zainoel Abidin Banda Aceh tahun 2018. Hasil penelitian ini menunjukkan terdapat hubungan yang signifikan antara informasi dan umur ibu dengan kecemasan ibu kanker payudara pada tindakan kemoterapi di Rumah Sakit Umum Daerah Zainoel Abidin Banda Aceh tahun 2018. Ibu yang pernah mendapatkan informasi mengenai tindakan kemoterapi $88,5 \%$, dibandingkan yang tidak pernah mendapatkan informasi mengenai tindakan kemoterapi yaitu $40 \%$.
\end{abstract}

Kata kunci: informasi, umur ibu, kecemasan pada tindakan kemoterapi

\begin{abstract}
WHO data in 2011 estimated that the incidence of breast cancer was 11 million and by 2030 it would increase to 27 million deaths from cancer. In Indonesia, the global data is the burden of cancer (globocan), breast cancer is the most common cancer in women (26 per 100,000). In Aceh, in particular Zainoel Abidin General Hospital as many as 809 people suffering from breast cancer, namely: 361 people hospitalized with the number of visits in the first quarter 129 people, second quarter 88 people, third quarter 61 people, fourth quarter 75 people and 448 people outpatient with the number of visits first quarter 97 people, second quarter 208 people, third quarter 72 people, quarter IV 89 people. To determine the relationship of information and age with maternal breast cancer anxiety in chemotherapy at the Zainoel Abidin Regional General Hospital in Banda Aceh in 2018.The results of this study indicate that there is a significant relationship between information and age of mothers with anxiety of breast cancer mothers in chemotherapy at the Zainoel Abidin Regional General Hospital Banda Aceh in 2018. Mothers who had received information about chemotherapy measures $88.5 \%$, compared who never got information about the action of chemotherapy which is $40 \%$.
\end{abstract}


Keywords: information, mother's age, anxiety on chemotherapy

\section{PENDAHULUAN}

Indonesia sebagai salah satu negara berkembang mengalami perubahan pola penyakit yang dikenal dengan transisi epidemiologi, yaitu perubahan pola penyakit dan penyebab kematian. Pada awalnya penyebab kematian didominasi oleh penyakit infeksi, namun kemudian didominasi oleh penyakit infeksi, namun kemudian bergeser ke penyakit non infeksi dan penyakit degeneratif salah satunya adalah penyakit kanker (Noviani, 2007).

Kanker merupakan masalah kesehatan masyarakat yang besar, yang perlu ditanggulangi secara menyeluruh, terpadu, efektif, efisien, ekonomis dan manusiawi, Kanker merupakan juga ancaman serius bagi kesehatan masyarakat karena insiden dan angka kematiaannya terus merayap naik. Oleh sebab itu penyakit kanker memerlukan penanganan sendiri dengan cara menghambat pembelahan sel-sel Abnormal (Jong, 2010).

Unsur terkecil dari jaringan tubuh ialah sel yang berfungsi membentuk tubuh dan memperbaiki jaringan tubuh yang rusak. Dalam perkembangannya, sel yang normal akan membelah diri secara teratur dan terkendali. Tetapi tidak demikian pada pembelahan sel kanker ia tidak bisa dikendalikan dan tumbuh berlipat ganda secara cepat dan terus menerus yang dapat menjadi suatu bentuk yang mendesak, serta merusak jaringan tubuh yang normal. Sehingga mengganggu fungsi organ yang jaringannya dirusak oleh sel kanker tadi. Akibatnya tentu saja merusak organ tubuh disekitarnya (Sukardja, 2000).

Kanker payudara merupakan gangguan payudara yang paling ditakuti perempuan. Salah satu penyebabnya karena penyakit ini tidak dapat disembuhkan jika ditemukan pada stadium lanjut. Padahal, jika dideteksi secara dini, penyakit ini sebetulnya bisa diobati sampai sembuh. Penyebab pasti penyakit ini belum diketahui. Penyebab yang ada hanya merupakan dugaan-dugaan, biasa disebut sebagai faktor-faktor resiko terkena kanker payudara (Boyles, 2008).

Pada tahun 2010 WHO (World Health Organization) memperkirakan angka kejadian yang terkena kanker payudara terdapat 11 juta dan tahun 2030 akan bertambah menjadi 27 juta kematian akibat kanker (Yohannes, 2008).

Laporan terbaru dari International Agency for Research on Cancer (IARC) mengeksplorasi beban kanker secara global, yang diperkirakan akan menjadi penyebab kematian utama pada tahun 2010.Laporan ini memperkirakan bahwa pada tahun 2030, 27 juta kasus kanker baru dan 17 juta kematian akibat kanker akan terjadi tiap tahunnya diseluruh 
dunia. Berdasarkan angka diagnosis kanker kemungkinan akan meningkat 1\% tiap tahunnya, begitu pula kematian akibat penyakit ini. China, Rusia, dan India diperkirakan akan memiiki peningkatan kanker dan kematian akibat kanker (Boyles, 2008).

Data dari yayasan kanker Indonesia pada lima tahun terakhir menyebutkan kejadian kanker payudara menempati urutan pertama 32\%, dari total jumlah kasus kanker. Total penderita kanker payudara $40 \%$ berobat pada stadium awal dan $30 \%$ dari total jumlah penderita kanker terdeteksi stadium lanjut lokal, dan 30\% dengan metastasis

(Haryono, 2007).

Di Indonesia, berdasarkan data global burden of cancer (globocan), kanker payudara merupakan kanker yang terbanyak terjadi pada perempuan (26 per 100.000). hal itu juga sesuai dengan data sistem informasi rumah sakit (SIRS), yang menyatakan dalam kurun waktu 2004-2007 kanker payudara menempati tempat pertama dari 10 jenis kanker terbanyak yang tercatat di rumah sakit. Data Departemen Kesehatan menyebutkan kanker merupakan penyebab kematian ke-5 di Indonesia, setelah jantung, stroke, saluran pernafasan dan diare (DepkesRI, 2006).

Berdasarkan data dari dinas Kesehatan Banda Aceh Jumlah pasien yang terkena kanker adalah Tahun 2004, 5200 kasus, Tahun 2005, 7900 Kasus, Tahun 2006 dan 2007, 8300 kasus. Dari Hasil data yang di dapat bahwa inflansi kenaikan kanker payudara yang sangat tajam pada tahun 2004 ke tahun 2005 dan Kanker payudara juga merupakan jenis kanker tertinggi yang di derita oleh masyarakat Aceh.

Di Aceh khususnya RSUD Zainoel Abidin sebanyak 809 orang yang menderita kanker payudara, yaitu : 361 orang rawat inap dengan jumlah kunjungan triwulan I 129 orang, triwulan II 88 orang, triwulan III 61 orang, triwulan IV 75 orang dan 448 orang rawat jalan dengan jumlah kunjungan triwulan I 97 orang, triwulan II 208 orang, triwulan III 72 orang, triwulan IV 89 orang (Rekam Medis RSUZA, 2017).

Berbagai pilihan terapi dapat dilakukan untuk mengatasi kanker. Pilihan pengobatan kepada pasien kanker harus berdasarkan pada tujuan yang realistik dan yang dapat dicapai untuk setiap tipe kanker yang spesifik. Banyak terapi yang dilakukan terhadap kanker, diantaranya operasi, radioterapi, kemoterapi dan terapi biologis serta beberapa metode terapi lainnya. Terapi operasi dan radioterapi dapat menjadi terapi kuratif kanker yang bersifat lokal, sedangkan kemoterapi digunakan untuk terapi sistemik terhadap kanker sistemik dan kanker 
dengan metastasis klinis ataupun subklinis. Pengobatan kanker stadium lanjut lokal, kemoterapi sering menjadi satu-satunya metode pilihan yang efektif (Smeltzer \& Bare, 2002).

Kemoterapi adalah penggunaan preparat antineoplastik sebagai upaya untuk membunuh sel-sel kanker dengan mengganggu fungsi dan reproduksi selular.Kemoterapi terutama digunakan untuk mengobati penyakit sistemik dari lesi setempat.Kemoterapi mungkin dikombinasi dengan pembedahan atau terapi radiasi, atau kedua-duanya. Tujuan dari kemoterapi (penyembuhan, pengontrolan, paliatif) harus realistik, karena tujuan tersebut akan menetapkan medikasi yang digunakan dan keagresifan dari rencana pengobatan (Smeltzer \& Bare, 2002).

Data dari ruang tindakan kemoterapi Rumah Sakit dr.zainoel abidin dari bulan januari 2017 sampai Desember, tindakan kemoterapi kanker payudara yang telah dilakukan sebanyak 228 tindakan (Catatan Medis RSUD dr. zainoel abidin 2017).

Kecemasan sebagai gangguan alam perasaan yang ditandai dengan perasaan ketakutan dan kekhawatiran yang mendalam dan berkelanjutan, tidak mengalami gangguan dalam menilai realitas, kepribadian masih tetap utuh, prilaku dapat menganggu tetapi masih dalam batas-batas normal (Hawari, 2006).

Berdasarkan penelitian yang telah dilakukan Heristanti (2005), tentang faktor-faktor yang berhubungan dengan tingkat kecemasan terhadap kemoterapi pada pasien kanker di Rumah Sakit Dr Kariadi Semarang. Variabel yang diteliti dalam penelitian ini adalah usia, tingkat pengetahuan, tingkat ekonomi, tingkat pendidikan dan lamanya kemoterapi. Penelitian menggunakan metode korelasional dengan rancangan cross-sectional, dengan jumlah sampel 34 orang. Diperoleh kesimpulan bahwa terdapat hubungan antara dua dari lima faktor yang diteliti dengan tingkat kecemasan terhadap kemoterapi pada pasien kanker di Rumah Sakit Dokter Kariadi Semarang yaitu faktor tingkat pendidikan $(\mathrm{p}=0,011)$ dan faktor lamanya kemoterapi ( $\mathrm{p}=0,001)$ sedangkan faktor tingkat pengetahuan, sosial ekonomi, dan faktor usia secara statistik tidak bermakna $(\mathrm{p}>0,05)$.

Pengkajian data awal yang dilakukan pada 4 pasien kanker yang menjalani kemoterapi di ruang mamplam 3, menunjukkan bahwa 75\% Pasien mengalami kecemasan. Pasien yang mengalami kecemasan merasa penderitaannya bertambah dengan adanya efek samping obat seperti mual, muntah, alopecia, kulit kering dan penurunan daya tahan tubuh , rasa tertekan karena adanya perasaan menambah beban keluarga dalam hal biaya dan waktu. Hasil 
wawancara menunjukkan kecemasan pasien juga bertambah ketika sikap sebagian perawat/bidan kurang mendukung dan menunjukkan sikap yang kurang empati kepada pasien.

Pasien juga merasa cemas karena akan melakukan operasi selanjutnya,apakah payudaranya akan di mastektomi atau masih dapat dipertahankan. Fenomena tersebut menjadikan dasar perlunya penelitian ini.

\section{METODE PENELITIAN}

Penelitian ini merupakan penelitian survey yang bersifat analitik dengan pendekatan CrossectionalPenelitian ini dilaksanakan pada Ruang Mamplam 3 di Rumah Sakit Umum Daerah dr. Zainoel Abidin Kota Banda Aceh yang dilaksanakan mulai tanggal 21 - 31 Juli 2018 .

\section{HASIL DAN PEMBAHASAN}

Berdasarkan hasil penelitian yang telah dilakukan di Rumah Sakit Umum Daerah Zainoel Abidin Banda Aceh, pada tanggal 21 s/d 31 Juli 2018, dengan jumlah responden sebanyak 36 orang, responden mayoritas mengalami cemas pada tindakan kemoterapi yaitu 27 orang $(75.0 \%)$.

Analisis bivariat menggunakan uji chi_square yang bertujuan untuk mengetahui hubungan variabel informasi dan umur ibu dengan kecemasan tindakan kemoterapi pada ibu kanker payudara. Hasil analisis bivariat tersebut disajikan pada tabel 1. sebagai berikut:

Tabel 1. Hasil Analisis Bivariat Hubungan Informasi dan Umur Ibu dengan Kecemasan Tindakan Kemoterapi pada Ibu Kanker Payudara di Rumah Sakit Umum Daerah Zainoel Abidin Banda Aceh Tahun 2018

\begin{tabular}{|c|c|c|c|c|c|c|c|}
\hline \multirow[t]{2}{*}{ Variabel Independen } & \multicolumn{4}{|c|}{ Kecemasan Ibu } & \multicolumn{2}{|c|}{ Total } & \multirow{2}{*}{$\begin{array}{c}\text { P- } \\
\text { Value }\end{array}$} \\
\hline & Cemas & $\%$ & Tidak Cemas & $\%$ & $\mathbf{f}$ & $\%$ & \\
\hline \multicolumn{8}{|l|}{ Informasi } \\
\hline 1. Pernah & 23 & 88.5 & 3 & 11.5 & 26 & 100 & 0.006 \\
\hline 2. Tidak Pernah & 4 & 40.0 & 6 & 60.0 & 10 & 100 & \\
\hline \multicolumn{8}{|l|}{ Umur Ibu } \\
\hline 1. Dewasa Awal & 2 & 66.7 & 1 & 33.3 & 3 & 100 & \\
\hline $\begin{array}{l}\text { 2. Dewasa } \\
\text { Menengah }\end{array}$ & 21 & 87.5 & 3 & 12.5 & 24 & 100 & 0.037 \\
\hline 3. Dewasa Akhir & 4 & 44.4 & 5 & 55.6 & 9 & 100 & \\
\hline
\end{tabular}




\section{Hubungan Informasi dengan Tindakan Kemoterapi pada Ibu Kanker Payudara di Rumah Sakit Umum Daerah Zainoel Abidin Banda Aceh tahun 2018}

Hasil analisis hubungan terlihat bahwa responden yang mengalami cemas terhadap tindakan kemoterapi lebih banyak dijumpai pada ibu kanker payudara yang pernah mendapatkan informasi mengenai tindakan kemoterapi yaitu 23 orang (88.5\%), dibandingkan dengan ibu kanker payudara yang tidak pernah mendapatkan informasi mengenai tindakan kemoterapi yaitu 4 orang (40.0\%).

Hasil uji statistik dengan menggunakan uji chi-square menunjukkan perbedaan presentase tersebut bermakna dengan nilai $\mathrm{p}=0.006$ artinya terdapat hubungan bermakna antara informasi dengan tindakan kemoterapi pada ibu kanker payudara di Rumah Sakit Umum Daerah Zainoel Abidin Banda Aceh tahun 2018.

Penelitian ini sejalan dengan penelitian yang dilakukan Sirait (2009) tentang hubungan informasi dengan kecemasan menghadapi tindakan kemoterapi pada pasien kanker payudara, hasil penelitian menunjukkan pasien yang mendapatkan informasi tentang tindakan kemoterapi lebih banyak mengatakan cemas dan khawatir akan tindakan kemoterapi.

Menurut Hawari (2006), kecemasan ibu terhadap tindakan kemoterapi disebabkan oleh informasi yang diperoleh tentang efek samping dari tindakan kemoterapi berupa rambut yang rontok, lalu kulit menjadi kering dan berubah warna. Efek samping ini yang membuat pasien kanker payudara merasa cemas akan tindakan kemoterapi. Hasil penelitian menunjukkan pasien-pasien yang tidak mendapatkan informasi akan efek samping dari tindakan kemoterapi tidak merasakan cemas, dikarenakan ketidaktahuan tentang kemoterapi.

Pasien kanker payudara yang mendapatkan informasi tentang efek samping dari kemoterapi akan cenderung mengalami dampak psikologis berupa rasa takut akan kematian, takut menjadi beban, takut ditinggalkan, ketidak mampuan, dan gangguan harga diri. Hasil penelitian Tara (2001) menyatakan dampak psikologis yang dialami pasien kanker payudara setelah mendapatkan informasi akan efek samping kemoterapi berupa cemas, stress, malu dan merasa tidak berguna lagi.

Hal tersebut juga sesuai dengan pendapat Hadjam (2000) dalam Sukardja (2000) mengungkapkan bahwa pasien kanker payudara yang tahu akan efek kemoterapi akan mengalami perasaan sedih, merasa lebih buruk dari orang lain. Stephen (2012) menyatakan 
bahwa pasien kanker payudara yang mendapatkan informasi akan efek dari kemoterapi cenderung mengalami penurunan yang signifikan terhadap dirinya jika dibandingkan dengan pasien yang tidak mendapatkan informasi akan efek samping dari tindakan kemoterapi.

Asumsi peneliti, dari uraian tersebut diatas, penderita kanker yang mendapatkan informasi akan efek samping tindakan kemoterapi akan mengalami kendala terhadap dirinya sendiri yang merasa putus asa dan merasa pengobatan ini hanya sia-sia, serta ketidakmauan penderita dalam mengatasi ketakutannya untuk tidak bisa sembuh.

Untuk itu peran keluarga sangat dibutuhkan untuk memberikan motivasi kepada pasien agar tidak perlu stress, karena kondisi yang demikian dapat mengganggu kelancaran pengobatan dengan kemoterapi. Selain itu dengan adanya konsultasi kepada dokter ahli, akan menambah keyakinan pasien kanker payudara untuk menjalani tindakan kemoterapi yaitu berupa penerangan bahwa efek samping dari tindakan kemoterapi dapat diminimalisir dengan terapi-terapi aman yang dilakukan dokter ahli.

\section{Hubungan Umur Ibu dengan Tindakan Kemoterapi pada Ibu Kanker Payudara di}

\section{Rumah Sakit Umum Daerah Zainoel Abidin Banda Aceh tahun 2018}

Hasil analisis hubungan terlihat bahwa responden yang mengalami cemas terhadap tindakan kemoterapi lebih banyak dijumpai pada ibu kanker payudara yang berumur kategori dewasa menengah yaitu 21 orang (87.5\%), dibandingkan dengan ibu kanker payudara yang berumur kategori dewasa akhir yaitu 4 orang (44.4\%) dan ibu berumur kategori dewasa awal yaitu 2 orang $(66.7 \%)$.

Hasil uji statistik dengan menggunakan uji chi-square menunjukkan perbedaan presentase tersebut bermakna dengan nilai $\mathrm{p}=0.037$ artinya terdapat hubungan bermakna antara umur ibu dengan tindakan kemoterapi pada ibu kanker payudara di Rumah Sakit Umum Daerah Zainoel Abidin Banda Aceh tahun 2018.

Hasil penelitan ini juga sesuai dengan hasil penelitian yang dilakukan Jong (2010) yang menunjukkan sebagian besar responden yang menderita kanker payudara berada pada kelompok umur dewasa menengah dengan umur 41-65 tahun sebanyak 44 orang (73,3 persen).

Masa dewasa tengah adalah rentang usia yang paling panjang dalam usia periode perkembangan. Prince \& Wilson (2006) menuliskan batasan usia dewasa tengah dimulai 
sekitar usia 40 hingga 65 tahun. Individu dengan usia ini merasa dirinya mampu berkembang secara optimal dan mandiri sehingga wajar apabila mereka menjadi cemas menghadapi tindakan kemoterapi. Kebanyakan individu di usia ini merasa sangat khawatir bila efek samping dari kemoterapi akan membuat dirinya tidak menarik, sehingga akan timbul perasaan-perasaan marah pada keadaan dan tidak jarang disertai penolakan akan tindakan kemoterapi, dukungan keluargalah yang harus dominan agar pengobatan dapat dilakukan.

Desen (2008) menyatakan bahwa masa ini disebut juga masa peralihan dari masa produktif menuju masa non produktif. Umur merupakan salah satu faktor risiko terkena kanker payudara. Banyaknya pasien yang berusia 40 tahun ke atas dikarenakan pada usia ini risiko terkena kanker payudara semakin besar (Indrati, 2005). Faktor usia sebagai risiko terkena kanker payudara diperkuat dengan data bahwa 78\% kanker payudara terjadi pada pasien dengan usia lebih dari 50 tahun dan hanya 6\% pada pasien dengan usia kurang dari 40 tahun (Sabiston, 1995 dalam Indrati, 2005).

Berdasarkan program Surveillance, Epidemiology, and End Results (SEER) yang dilakukan National Cancer Institutte (NCI) insidensi kanker payudara meningkat seiring dengan pertambahan usia, diperkirakan 1 dari 8 wanita mengalami perkembangan penyakit kanker payudara sepanjang hidupnya. Kemungkinan terbesar perkembangan penyakit payudara mulai terjadi pada wanita dengan kisaran umur 40-50 tahun (Harianto, Rina, dan Hery, 2005 dalam Indrati, 2005).

Kasus kanker payudara akan meningkat pada usia reproduktif, kemudian setelah itu meningkat dengan kecepatan yang lebih rendah (Indrati, 2005). Selaras dengan penelitian Budiningsih (1995) dalam Indrati (2005) dimana kasus terbanyak pada umur 40-49 tahun. Risiko kanker payudara berkembang sampai usia 50 tahun dengan perbandingan peluang 1 diantara 50 wanita. Lebih dari $75 \%$ kanker payudara terdiagnosa pada wanita berumur 40 tahun ke atas.Kanker payudara jarang terjadi pada wanita berusia di bawah 30 tahun (Lincoln dan Wilensky, 2007 dalam Fitriani, 2012).

Sejalan dengan hasil penelitian Yunitasari (2007) yang menyatakan bahwa prevalensi wanita penderita kanker payudara yang tertinggi terjadi pada usia lebih dari 40 tahun sebanyak 84\%. Penelitian Sirait (2009) memperlihatkan bahwa umur rata-rata pasien kanker payudara adalah 41,92 tahun. Penelitian di Yogyakarta dan Bantul menunjukkan 
bahwa penderita kanker payudara yang berumur $<40$ tahun sebesar $23,4 \%$ dan $\geq 40$ tahunsebesar 76,6\% (Sari, 2006 dalam Sirait, 2009).

Usia dewasa tengah berkaitan dengan menopause. Umumnya wanita yang berusia 40 tahun ke atas mengalami menopause. Wanita yang mengalami awal menopause pada usia lebih tua berarti lebih lama terpapar dengan tingginya kadar estrogen dalam darah. Peran estrogen pada wanita menopause adalah menghambat terjadinya menopause sehingga mengembangkan risiko terjadinya kanker payudara (Lincoln dan Wilensky, 2008 dalam Fitriani, 2012). Semakin tua usia seseorang saat awal menopause maka semakin besar risiko terkena kanker payudara dibanding dengan wanita yang mengalami menopause lebih muda (Indrati, 2005).

Jong (2010) menjelaskan, masa dewasa tengah menuju dewasa akhir merupakan masa dimana seseorang telah memiliki tingkat kecerdasan moral, spiritual, dan agama secara mendalam. Semakin lama usia seseorang, maka semakin terbentuk sikap keharusan untuk menyesuaikan diri dengan kenyataan bahwa cepat atau lambat hidupnya akan berakhir dan mulai muncul pengakuan terhadap realitas kehidupan akhirat secara lebih sungguh-sungguh, sehingga usia dewasa akhir kebanyakan individu merasa pasrah akan keadaan yang dialaminya, hal inilah yang membuat usia dewasa akhir tidak cemas akan tindakan kemoterapi.

Asumsi peneliti, umur dewasa menengah merupakan umur yang paling sering terserang kanker payudara diperparah lagi apabila umur pertama kali melahirkan terlalu tua. Pada umur dewasa menengah merupakan masa reproduksi dimana umur payudara akan lebih tua 2-3 tahun dari organ tubuh wanita lainnya, sehingga apabila seorang wanita tidak melahirkan di usia yang tepat, maka akan meningkatkan risiko terserang kanker payudara. Pada usia dewasa menengah lebih sering ditemukan individu yang sangat cemas akan tindakan kemoterapi karena mereka menganggap tindakan ini dapat membuat dirinya tidak berguna, sehingga timbul penolakan akan tindakan kemoterapi. Sikap demikian sangatlah wajar, dikarenakan efek samping kemoterapi yang ditimbulkan seperti warna kulit yang berubah dan rambut menjadi rontok membuat individu pada umur tersebut menjadi takut tidak dicintai lagi oleh pasangannya, sehingga banyak dari mereka yang menawar untuk tidak dilakukan kemoterapi.Disini peran anggota keluargalah yang menjadi sangat penting, agar pasien kanker payudara tersebut mau untuk dilakukan tindakan kemoterapi.Tidak hanya itu, dokter ahli juga memiliki peran yang dominan, yaitu dengan 
menyakinkan pasien untuk mau kemoterapi dan menawarkan terapi-terapi yang dapat mengurangi efek samping yang ditimbulkan dari kemoterapi.

\section{SARAN}

1. Instansi Rumah Sakit

Pihak rumah sakit diharapkan dapat meningkatkan kegiatan yang bertujuan untuk meningkatkan semangat hidup pasien kanker payudara misalnya melalui aktivitas kerohanian seperti pengajian atau penyuluhan yang bersifat memotivasi agar mereka dapat memaknai hidupnya dengan baik.

2. Profesi Kebidanan

Petugas kesehatan khususnya profesi kebidanan diharapkan dapat aktif berperan serta di lingkungan masyarakat dalam memberikan pendidikan kesehatan terutama mengenai kanker payudara dan memberikan dukungan serta motivasi kepada para penderita kanker payudara supaya mereka mengerti dan memahami bahaya kanker, cara pencegahan dan pengobatan, menyadari pentingnya kesehatan, dan termotivasi untuk menjalani hidupnya dengan baik. Sebagai bidan kita harus memberikan kesadaran pada masyarakat akan pentingnya deteksi dini kanker payudara dan lebih meningkatkan pengetahuan mengenai kanker.

3. Peneliti selanjutnya

Perlu adanya penelitian lebih lanjut dengan menambah variabel lain yang mempengaruhi kecemasan ibu kanker payudara terhadap tindakan kemoterapi.

\section{DAFTAR PUSTAKA}

Benson Ralph C, (2009), Buku Saku Obstetri Dan Ginekologi, Jakarta: EGC.

Boyles. (2008). Epidemiology of lung cancer: a century of great success and ignominious failure. In: Hansen H, editor. Textbook of lung cancer. United Kingdom: Informa UK Ltd; 2008.p.9-10.

Catatan Medis RSUD dr.Zainoel Abidin. (2012). Data di Ruang Tindakan Kemoterapi Bulan Januari 2012 sampai Desember 2012.

Depkes RI. (2006). Glosarium 2006. http://www.depkes.go.id/downloads/publikasi/Glosarium\%202006.pdf [3 Mei 2013].

Desen, Wan. (2008). Onkologi Klinis. Edisi 2. Jakarta: FKUI 
Dixon M, dkk. (2005). kelainan payudara, cetakan I, Jakarta: Dian Rakyat.

Fausiah, Fitri dkk. (2011). Psikologi Abnormal Klinis Dewasa. Jakarta: Universitas Indonesia.

Fitriani. (2012). Hubungan dukungan keluarga dengan tingkat kecemasan pasien kanker payudara dalam menjalani kemoterapi di Rumah Sakit Cipto Mangunkusumo.

Ghofar, A. (2009) cara mudah mengenali dan mengobati kanker, Jogjakarta : Lamingo.

Haryono.(2007). Panik Neurosis dan gangguan Cemas. Jakarta: Dua As-As

Jakarta.

Hawari, D,( 2006). Manajemen Stres, Cemas, \& Depresi (Edisi 2), Jakarta: Gaya Baru.

Intan, dkk (2012) Kesehatan Reproduksi Untuk Mahasiswa Kebidanan Dan Keperawatan, Penerbit Salemba Medika.

Jong, De Wim. (2010). Kanker apakah itu? Pengobatan, Harapan Hidup Dan Dukungan keluarga, Cetakan pertama. Jakarta :Arcan.

Manuaba, dkk.( 2009). Memahami Kesehatan Reproduksi Wanita. Edisi 2. Penerbit Buku Kedokteran. Jakarta: EGC.

Manuaba, dkk, ( 2010.) Ilmu Kebidanan, Penyakit Kandungan, dan KB untuk Pendidikan Bidan. Edisi 2. Penerbit Buku Kedokteran. Jakarta: EGC

Mansjoer,dkk, (2000), kapita selekta kedokteran, Edisi Revisi, Jakarta: EGC.

Noviani. (2007). Pedoman Surveilans Epidemiologi Penyakit Kanker. Jakarta: Direktorat Pengendalian Penyakit Tidak Menular Jenderal PP\&PL. Depkes RI.

Prawirohardjo ,S. (2008). Ilmu Kandungan. Edisi 2. Jakarta: PT Bina Pustaka.

Prince \& Wilson. (2006). Childhood cancer in Britain: Incidence survival, mortality. In: Arora

R.S., Eden T.O.B., Kapoor G., 2009. Epidemiology of childhood cancer in India. Indian Journal of Cancer October-December 2009; 46 (4): 264.

Rasjidi,I. (2009). Deteksi Dini Dan Pencegahan Kanker pada wanita, Jakarta: Sagung Seto. (2007). Kemoterapi Kanker Ginekologi Dalam Praktik Sehari-Hari, Jakarta : Sagung seto.

Rekam Medis RSUDZA. (2012). Data Penderita Rawat Inap Kanker Payudara.

Sirait. (2009). Faktor-faktor yang berhubungan dengan tingkat kecemasan terhadap kemoterapi pada pasien kanker Payudara di Rumah Sakit dr. Kariadi. Semarang: Fakultas Kedokteran Universitas Diponegoro

Tapan. (2005). kanker anti oksidan dan terapi komplementer, Jakarta: Elex media kompitundo. 
Tim Penanggulangan dan Penanggulangan Kanker Payudara Terpadu Paripurna RS. Kanker Dharmais (2002) (2003) penatalaksanaan kanker payudara terkini, Jakarta: pustaka popular obor.

Vide Beck. (2008). "Diagnostic and stastical manual ofmental disorder", (4th ed.), Author, Washington.

Winarto, W., Vivi, K., Erna, C., Heri, J., dan Nurrohman, S. (2007).Pengobatan untuk kanker payudara.Edisi 2. Jakarta: Salemba Medika.

Yohannes.(2008). Social support as a mediator of optimism and distress in breast cancer survivors. Journal of Consulting and Clinical Psychology, 71(4), 805-811.

Yunitasari.(2007). Faktor-faktor yang mempengaruhi tingkat kecemasan pasien pasca diagnose kanker di Rumah Sakit dr. Kariadi. Semarang: Fakultas Kedokteran Universitas Diponegoro. 